Kiryoku, Volume 3 No 12019

e-ISSN: 2581-0960 p-ISSN: 2599-0497

Tersedia online di http://ejournal.undip.ac.id/index.php/kiryoku

\title{
SIKAP BAHASA PENUTUR SHIMAKUTUBA DIALEK UCHINAGUCHI DI PREFEKTUR OKINAWA
}

\author{
Reny Wiyatasari*; Mentari Diufuk Timur \\ Universitas Diponegoro \\ *Email : reny.wiyatasari@gmail.com
}

\begin{abstract}
Abstrak
Penelitian ini bertujuan untuk mengetahui sikap bahasa penutur dialek Uchinaguchi, salah satu dialek dalam bahasa Shimakutuba yang digunakan di kepulauan Okinawa. Shimakutuba adalah salah satu bahasa di dunia yang ditetapkan oleh UNESCO sebagai bahasa yang terancam punah(endangered language). Karena tema penelitian ini difokuskan pada sikap bahasa yang merupakan salah satu topik dalam kajian sosiolinguistik, maka pengumpulan data dilakukan denganmetode kuesioner melalui penyebaran kusionerkepadaresponden yang dianggap representatif mewakili populasi penelitian dan juga menggunakan metode studi pustaka. Selanjutnya data dianalisis menggunakan metode deskriptif.Berdasarkan hasil kusionerdiketahui sikap bahasa yang ditunjukkan penutur Shimakutuba terbagi menjadi dua, yakni sikap positif dan sikap negatif. Sikap positif terdiri atas positif mendukung dan positif tidak mendukung.
\end{abstract}

Kata Kunci: Revitalisasi; Shimakutuba; Uchinaguchi; Endangered language ; Sikap bahasa

\begin{abstract}
(Title: Language Attitudes Of The Speakers Of Uchinaguchi Dialect, Shimakutuba Language In Okinawa Prefekture) This study aims to determine the language attitude of the speakers of the Uchinaguchi dialect, one of the dialects in Shimakutuba which is the language used in the Okinawa islands. Shimakutuba is one of the languages in the world set by UNESCO as an endangered language. Because the theme of this research is focused on language attitudes which is one of the topics in sociolinguistic studies, the data are collected using the questionnaire method through distributing questionnaires to respondents who are considered representative representing the research population and also using literature study methods. Then the data were analyzed using descriptive methods. Based on the results of the questionnaire, it was found that the language attitude shown by speakers of Shimakutuba was divided into two, namely positive attitudes and negative attitudes. A positive attitude consists of positive active and positive passivity.
\end{abstract}

Keywords: Revitalization; Shimakutuba; Uchinaguchi; Endangered language; Language attitude

\section{PENDAHULUAN}

Jepang merupakan negara dengan berbagai variasi budaya dan dialek. Kalau selama ini pembelajar bahasa Jepang mengenal bahwa bahasa Jepang adalah bahasa standar satu-satunya yang digunakan oleh penduduk Jepang dari ujung utara, yaitu pulau Hokaido hingga 
ujung selatan, yaitu pulau Kyushu, maka sesungguhnya ada bahasa lainnya yang digunakan, dan salah satunya adalah bahasa Shimakutuba. Shimakutuba yang dalam bahasa Jepang berarti bahasa pulau merupakan bahasa yang digunakan di Kerajaan Ryuukyuu yang sekarang telah menjadi salah satu bagian dari Jepang dan berganti nama menjadi Prefektur Okinawa. Sampai dengan sekarang, bahasa Shimakutuba masih eksis dan memiliki beragam dialek. Bahasa Shimakutuba adalah bahasa tersendiri dan bukan termasuk salah satu dialek dalam bahasa Jepang, seperti halnya bahasa Jawa yang digunakan oleh masyarakat Jawa Tengah atau Yogyakarta.

Penggunaan kata Shimakutuba (bahasa Ryukyu), menurut Uemura (2003:22) merujuk pada dialek-dialek yang ada di kepulauan Okinawa secara menyeluruh yang kurang lebih berjumlah sekitar 11 dialek dan terbagi menjadi dua sub-penggunaan, yakni Amami-Okinawa Dialect Group(kumpulan dialek didaerah utara kepulauan Okinawa) dan MiyakoYaeyama Dialect Group(kumpulan dialek yang digunakan di daerah selatan kepulauan Okinawa).

Kerajaan Ryukyu pada awalnya didominasi oleh pengaruh Cina, sehingga teks-teks lama kerajaan Ryukyu ditulis menggunakan karakter Cina (Kanji). Penggunaan huruf kana sendiri diperkenalkan oleh pihakmainland Jepang saat mengambil alih kerajaan Ryukyu pada periode Meiji, sebelum penutur Shimakutubadapat mengembangkan bahasa tulisan mereka sendiri. Hal ini menyebabkan generasi muda sekarang menganggap bahwa Shimakutuba hanyalah merupakan subbahasa dalam bahasa Jepang daripada menganggapnya sebagai bahasa tersendiri. Keadaan ini dibuktikan oleh penelitian yang dilakukan oleh Masahide Ishihara, seorang profesor dari University of The Ryukyus dalam bukunyaSelf-determinable Development of Small Island. Disebutkan bahwa dari survei yang dilakukan kepada 605 orang yang berhubungan langsung dengan budaya tradisional Okinawa dalam kesehariannya, hanya 5 persen dari rentang usia dibawah 30 tahun yang mengaku dapat berbahasa Ryukyu (Shimakutuba) dengan lancar.Karena itulah, penutur Shimakutuba semakin berkurang dari tahun ke tahun dan hal ini menyebabkan bahasa Shimakutuba dimasukkan dalam daftar endangered language (bahasa yang hampir punah) oleh UNESCO sejak tahun 2009.

Menanggapi hal tersebut, para pembelajar bahasa Jepang bersama dengan pemerintah Okinawa serta pemertahan bahasa Shimakutuba mulai mengkaji cara untuk merevitalisasikan bahasa Shimakutuba agar tidak menghilang begitu saja, sehingga dapat diwariskan kepada generasi selanjutnya.

Penyebab yang melatarbelakangi status bahasa Shimakutuba sebagai salah satu endangered language (bahasa yang terancam punah) terdiri dari berbagai macam faktor, antara lain merupakan faktor historis dan politik.

Terjadinya perang pasifik di Okinawa pada akhir perang dunia kedua merupakan salah satu penyebab terbesar berkurangnya penutur asli Shimakutuba dikarenakan banyaknya korban jiwa yang berjatuhan selama masa perang. Sementara faktor politik lebih didasari oleh keinginan pemerintah Jepang untuk menanamkan rasa nasionalisme tinggi kepada Okinawa yang kembali menjadi bagian dari Jepang setelah sebelumnya diduduki oleh Amerika dengan melarang penggunaan Shimakutuba sebagai bahasa sehari-hari dan bahasa pengantar utama serta menggantinya dengan bahasa Jepang standar di sekolah-sekolah, perkantoran hingga universitas.

Dalam artikel ini, penulis lebih memfokuskan sikap bahasa para pemertahandialek Uchinaguchi. Uchinaguchi merupakan dialek yang digunakan di Ibu kota kerajaan Ryukyu (Okinawa) yang menjadi dialek representatif dari seluruh subdialek yang 
ada pada masanya, dan juga sebagai subdialek terbanyak yang masih digunakan pada masa modern ini.

Salah satu penelitian yang bersinggungan dengan tema yang diangkat dalam artikel ini adalah penelitian yang dilakukan oleh Masahide Ishihara (2016) dalam buku Self-determinable Development of Small Islandsyang berjudul Language Revitalization Effort in the Ryukyus (Usaha Revitalisasi bahasa di Ryukyus). Dalam penelitian tersebut, Ishihara membahas upaya-upaya yang dilaksanakan pemerintah Okinawa dan organisasi swasta. Penelitian ini berfokus pada usaha-usaha yang dilakukan oleh pemerintah okinawa untuk merevitalisasi Uchinaguchi.

Penelitian kedua adalah penelitian yang dilakukan oleh Patrick Heinrich (2005) dari Duisburg-Essen University, Jerman, dalam jurnal yang dipublikasikan melalui The Asia-Pasific Journal: Japan Focus dengan judul Language Loss and Revitalization in the Ryukyus Island (Kepunahan Bahasa dan Revitalisasinya di kepulauan Ryukyus). Dalam penelitian tersebut, Heinrich membahas penyebab surutnya pengguna Shimakutuba, terutama yang terjadi pada variasi bahasa (tuturan) yang terletak di daerah Shuri, yakni Uchinaguchi, baik dari perspektif sejarah, yakni faktor perang pasifik, maupun segi sosial penutur Uchinaguchi

Penelitian ketiga adalah penelitian yang dilakukan oleh Mark Robert Anderson (2009) dari The University of Sydney, Australia, dalam tesisnya, Emergent Language Shift in Okinawa. Dalam penelitian tersebut, Anderson menekankan proses terjadinya pergeseran penggunaan bahasa yang terjadi di Okinawa, sebagai penelitian utamanya tentang penggunaan bahasa Jepang yang menggantikan shimakutuba sebagai bahasa utama di masyarakat.

Dari penelitian di atas, diketahui bahwa ketiganya lebih memfokuskan pada usaha-usaha revitalisasi bahasa di kepulauan Ryukyus atau tentang pemertahanan bahasa, namun belum ada yang membahas atau meneliti bagaimana sikap bahasa pemertahan bahasa Shimakutuba dialek Uchinaguchi terhadap usaha revitalisasi yang dilakukan oleh pemerintah atau pihak-pihak lainnya.Oleh karena itu, penelitian ini difokuskan pada sikap bahasa pemertahan bahasa Shimakutuba dialek Uchinaguchi terhadap usaha revitalisasi yang dilakukan baik oleh pemerintah Okinawa maupun pemertahan bahasa Shimakutuba. Diharapkan melalui artikel ini, pembelajar bahasa Jepang, khususnya yang berminat di bidang kajian sosiolinguistik bahasa Jepang dapat mengetahui bahasa Shimakutuba dialek Uchinaguchi, serta sikap bahasa yang ditunjukkan oleh penutur-penuturnya oleh terhadap revitalisasi Shimakutuba dialek Uchinaguchi.

\section{METODE}

Dalam pengumpulan data penulis menggunakanteknik survei sebagai penyedia data utamadan studi pustaka sebagai penyedia data sekunder. Metode survei dilakukan melaluipenyebaran kusioner atau daftar tanyaan terstrukturdan rinci. Para responden juga diberi kebebasan untuk menjawab, tidak harus dalam bahasa Jepang, namun diperbolehkan juga dalam bahasa Inggris. Daftar tanyaan yang diberikan di antaranya adalah berisi tentang kosakata dalam bahasa Shimakutuba dan responden diminta menterjemahkan dalam bahasa Jepang. Tujuannyametode survey ini untuk memperoleh informasi dari sejumlah besar responden yang dipandang representatif mewakili populasi penelitian. Jumlah responden adalah 54 orang, dengan rentang usia 16-25 tahun sejumlah $53,7 \%$, usia $26-$ 40 tahun sejumlah $24,1 \%$, usia 40-60 tahun sejumlah $18,5 \%$, serta usia di atas 60 tahun sejumlah $3,8 \%$.

Metode survei dilakukan menggunakan formulir survei yang dapat diakses dan dibagikan menggunakan tautan 
Kiryoku, Volume 3 No 12019

e-ISSN: 2581-0960 p-ISSN: 2599-0497

Tersedia online di http://ejournal.undip.ac.id/index.php/kiryoku

https://goo.gl/forms/7fmMhveYlu908eaN2y

ang disediakan secara online sebagai moda pencarian responden yang menggunakan penutur Shimakutubadialek Uchinaguchi, baik penduduk asli Okinawa, maupun pendatang yang berminat terhadap Uchinaguchi. Data-data yang digunakan dalam penelitian juga ini didapatkan dari berbagai sumber sebagai pendukungnya. Sementara metode studi pustaka tersendiri dilakukan dengan pengkajian kembali penelitian-penelitian sebelumnya.

Selanjutnya penulis menggunakan metode deskriptif untuk menganalisis data dengan cara dengan menjabarkan secara deskritif fenomena-fenomena yang dipotret berdasarkan analisis sikap penutur dan pemertahan Shimakutuba terhadap usaha revitalisasi yang dilakukan oleh pemerintah Okinawa dan Sektor Privat. Jumlah persentase penggunaan dihitung dari jumlah total responden yang menjadi subjek penelitian ini, dengan batasan status pemertahan Shimakutuba, baik pemertahan lokal maupun internasional.

\section{HASIL DAN PEMBAHASAN}

Sikap bahasa (language attitude) adalah posisi mental atau perasaaan terhadap bahasa sendiri atau bahasa orang lain (Kridalaksana, 2011: 221). Berdasarkan kuisoner yang disebarkan kepada 54 responden diketahui sikap bahasa penutur bahasa Shimakutubu dialek Uchinaguchi terbagi atas dua sikap, yaitu sikappositif dan sikapnegatif.

\section{Sikap positif}

Sikap positif dibagi atas dua kategori, yakni sikap positif aktif dan sikap positif pasif.Persentase responden bereaksi positif terhadap usaha-usaha yang dilakukan baik oleh pemerintah maupun pemertahan bahasa Shimakutuba untuk merevitalisasikan bahasa Shimakutuba mencapai angka $98.1 \%$ dari keseluruhan responden. Hal ini menunjukkan bahwa tingkat kesadaran masyarakat terhadap pentingnya usaha revitalisasi yang dilakukan untuk menyelamatkan
Shimakutuba dari kepunahan yang permanen sangat tinggi secara umum.

Sikap positif aktif dilihat dari tanggapan mereka terhadap seberapa pentingnya revitalisasi bahasa Shimakutuba serta tanggapan mereka tentang usaha yang dilakukan, baik oleh pemerintah maupun swastaserta para pemertahan Shimakutuba yang lain.

\section{a. Sikap positif aktif}

Sikappositif aktif ditandai dengan antusiasme responden terhadap kegiatankegiatan yang ditawarkan pemerintah Okinawa, pihak swasta maupun pemertahan shimakutuba sebagai bentuk revitalisasi Shimakutuba. Responden dengan kategori ini menyatakan bahwa revitalisasi bahasa Shimakutuba dinilai sangat penting dengan jumlah responden mencapai $44.2 \%$ dari keseluruhan responden. Selain itu dengan melihat tingginya minat responden tersebut untuk mengikuti kelas-kelas, maupun kegiatan ekstra yang diadakan baik di sekolahsekolah, melalui acara kegiatan tahunan pemerintah, serta berpartisipasi dengan kegiatan seni yang menggunakan Shimakutuba sebagai bahasa utamanya, seperti contohnya kesenian kumiodori. Kumiodori sendiri merupakan kesenian teatrikal khas Okinawa yang seluruh narasi maupun dialognya menggunakan bahasa Shimakutuba tanpa alih bahasa ke bahasa Jepang.

Salah satu responden yang menyatakan bahwa,

"I'm really proud of being Okinawan. Okinawa is the place where it's unique culture is blooming. We, as Okinawan, should never forget about who we are and where we come from, and what we've been through.Language is the most important key to success for the Okinawan Renaissance. 'saya sangat bangga menjadi seorang penduduk Okinawa. Okinawa merupakan tempat dimana kultur uniknya berkembang. Kami, sebagai penduduk Okinawa, seharusnya tidak melupakan tentang siapa kami dan dari mana kami 
berasal, serta apa yang telah kami lalui. Bahasa merupakan salah satu kunci yang sangat penting dalam kebangkitan kembali Okinawa",

Hal ini menunjukkan, bahwa tidak sedikit orang-orang Okinawa yang berpendapat bahwa pelestarian bahasa merupakan kunci utama dalam pelestarian sebuah budaya dan sejarah, juga sebagai pemertegas identitas dari sebuah bangsa itu tersendiri, karena tanpa tuturan itu sendiri, kemungkinan besar generasi yang akan datang akan kesulitan menguraikan kejadian-kejadian penting yang terjadi di masa lampau, dan kesulitan untuk mengenali identitas awal para pendahulunya.

Berdasarkan hasl survey diketahui bahwa para responden yang menanggapi dengan positif pemertahanan yang di lakukan baik oleh pemerintah maupun sektor privat juga berlomba-lomba menyampaikan usul dan masukan untuk memperkaya usaha-usaha yang di lakukan oleh kedua belah pihak, seagai bentuk partisipasi dalam menambah variasi usaha yang dapat dilakukan baik oleh pemerintah, sektor privat, maupun oleh masyarakat itu tersendiri.

\section{b. Sikap positif pasif}

Sikap positif pasif sendiri memiliki persentase paling banyak diantara kategori lainnya, yakni sebesar 53.8\% dari keseluruhan responden.Responden yang tergabung dalam kategori ini merasa bahwa revitalisasi yang dilakukan oleh pemerintah serta sektor privat merupakan hal yang penting, tetapi tidak termasuk prioritas yang harus dilakukan dalam pemerintahan itu sendiri.

Seperti yang diutarakan oleh salah satu responden,

"Unique language is good to have for identity making. But it is not a must. (bahasa yang unik sangat bagus sebagai bentuk identitas tetapi itu bukanlah sebuah keharusan)"
Kebanyakan responden dalam kategori ini berpendapat bawa ada hal-hal lain yang lebih mendesak, dan apabila kepunahan benar-benar menimpa bahasa Shimakutuba, baik para peneliti maupun pembelajar tetap dapat membahas Shimakutuba melalui literatur maupun buku-buku yang tersisa. Selain itu, karena sangat sedikitnya penutur asli yang tersisa di antara mereka yang menyebabkan sedikitnya narasumber serta pengetahuan mengenai linguistik dan antropologi bahasa yang bersangkutan, responden dalam kategori ini merasa bahwa revitalisasi Shimakutuba merupakan hal yang sulit untuk dilakukan.

\section{Sikap negatif}

Hanya $1.9 \%$ dari keseluruhan responden yang menjawab menyatakan bahwa revitalisasi yang dilakukan oleh pemerintah dan sektor privat merupakan hal yang tidak penting untuk dilakukan. Responden dalam kategori ini memandang secara skeptis usaha-usaha yang dilakukan oleh pemerintah Okinawa maupun sektor Privat. Hal ini dikarenakan tingkat kesulitan penggunaan Shimakutuba yang bukan merupakan bagian dari bahasa Jepang, ketiadaaan tempat untuk menggunakannyasecara berkesinambungan serta responden yang bersangkutan merasa bahwa sudah terlambat untuk melakukan revitalisasi dalam bentuk apapun.

Hal ini menunjukkan bahwa tidak sedikit pula responden yang berpikiran bahwa usaha dalam merevitalisasikan sebuah tuturan dam melestarikannya merupakan sebuah perkara yang tidak mudah, bahkan cenderung sangat sulit dan hampir dikatakan mustahil dengan menilik keadaan masyarakat modern sekarang. Dengan berdasarkan kenyataan seperti itulah, beberapa responden merasa sangat skeptis dalam revitalisasi kembali shimakutuba dialek uchinaguchi.

Meskipun begitu penulis berpendapat bahwa hal itu tidak selamanya benar, karena melihat dari kemampuan sebagian 
Kiryoku, Volume 3 No 12019

e-ISSN: 2581-0960 p-ISSN: 2599-0497

Tersedia online di http://ejournal.undip.ac.id/index.php/kiryoku

besar responden yang menjawab dengan benar saat penulis meminta para responden untuk menerjemahkan sebuah peribahasa dalam Shimakutuba yakni 'Ichari-ba choodee'「イチャリバチョーデー」 ke dalam bahasa Jepang, mayoritas dari responden dapat menjawab dengan tepat dan mengartikannya sebagai 'deatta naraba kyoudai’「出会ったならば兄 弟」'bila bertemu, maka menjadi saudara'.

Selain menerjemahkan peribahasa dari Shimakutuba ke dalam bahasa Jepang, para responden juga tidak memiliki kesulitan dalam menerjemahkan sapaan sederhana dari dalam bahasa Jepang ke dalam Shimakutuba. Kebanyakan dari mereka dapat menulis 'arigatou gozaimasu'「あ りがとうございます」 yang dalam bahasa Indonesia merupakan ungkapan 'terima kasih' dan menerjemahkannya ke dalam Shimakutuba sebagai 'Nifee dee biru’「ニフェーデービル」 yang dalam dialek Uchinaguchijuga berarti 'terima kasih'.

Dengan melihat jawaban responden terbanyak, penulis dapat menyimpulkan bahwa sedikit demi sedikit, revitalisasi dan pelestarian tuturan yang diusahakan oleh pemerintah dan berbagai macam sektor privat dapat dikatakan sebagai suatu kemajuan dalam penyelamatan Shimakutuba secara keseluruhan.

Penulis memilih peribahasa lama 'Ichari-ba choodee' sebagai tolok ukur dalam pemahaman Shimakutuba secara general, tidak lain dengan mempertimbangkan semangat para penduduk Okinawa yang benar-benar hidup berdasarkan nilai-nilai kehidupan yang tercermin dalam peribahasaperibahasa yang tertulis dalam Shimakutuba, hal ini tentu saja menjadi sebuah tolak ukur alami, bahwa Shimakutuba benar-benar merupakan tuturan yang sangat penting untuk di pertahankan, karena di dalamnya terdapat banyak sekali nilai-nilai kemanusiaan yang dapat dipetik darinya, dan akan sangat di sayangkan sekali apabila tuturan ini hilang begitu saja dari peradaban modern ini.

\section{SIMPULAN}

Sikap bahasa yang ditunjukkan oleh para pemertahan Shimakutuba dilihat dari berbagai macam opini mereka dalam usaha pemerintah dalam menghidupkan kembali Shimakutuba juga dapat dibilang cukup positif, meskipun tingkat kepositifan satu responden berbeda dengan responden lainnya, mengingat hampir seluruh responden bersikap positif aktif $44,2 \%$ dan positif pasif $53,8 \%$, yaitu mendukung untuk melanjutkan pembelajaran Shimakutuba kepada generasi selanjutnya, dan semangat mereka untuk terus mempelajari Shimakutuba sebagai bagian dari budaya dan cara hidup mereka sebagai penduduk Okinawa. Hal ini menunjukkan bahwa bahasa itu sendiribenar-benar merupakan sebuah alat yang dapat mempersatukan bangsa dan budaya, serta melestarikan keberadaan sejarah, dan menjadi identitas penting agar suatu bangsa diakui atau tidak di mata bangsa lainnya di dunia. Kesadaran atas pentingnya menjaga identitas diri sebagai penduduk Ryukyus(Okinawa) merupakan langkah awal dalam kembalinya kejayaan budaya dan sejarah yang telah di jaga selama berabad-abad di Okinawa.

Melihat banyak di antara responden yang menyambut baik usaha revitalisasi yang dilakukan baik oleh pemerintah Okinawa maupun sektor privat serta pemertahan Shimakutuba, dapat dikatakan bahwa revitalisasi Shimakutuba secara perlahan bergerak ke arah yang lebih positif, sehingga tidak mustahil apabila di masa depanbahasa Shimakutuba dapat diselamatkan dari ancaman kepunahan bahasa. 


\section{DAFTAR PUSTAKA}

Anderson, Mark Robert. (2009). Emergent Language Shift in Okinawa. Thesis, $S$ 3. Sydney: The University of Sydney.

Bradley, David and Maya Bradley. (2002). Language Endangerment and Language Maintenance. London and New York: Routledge.

Chaer, Abdul dan Leoni Agustia. (2010). Sosiolinguistik, Pengenalan Awal. Jakarta: Rineka Cipta.

Deckert, Sharon K. And Caroline H. Vickers. (2011). An Introduction to Sociolinguistics. New York: Continuum.

Djajasudarma, T. Fatimah. (2010). Metode Linguistik: Ancangan Metode Penelitian dan Kajian. Bandung: Refika Aditama.

Dorian, Nancy C. (1981). Language death: The life cycle of a Scottish Gaelic dialect. Philadelphia: University of Pennsylvania Press.

Fishman, Joshua A. (1991). Reversing Language Shift: Theoretical and Empirical Foundations of Assistance to Threatened Languages. Clevedon: Multilingual Matters Ltd.

Heinrich, Patrick and Christian Galan. (2011). Language Life in Japan: Transformations and Prospects. Routledge

Heinrich, Patrick. (2005). Language Loss and Revitalization in the Ryukyu Islands. The Asia-Pacific Journal, Japan Focus.

Hymes, Dell. (1977). Foundations in Sociolinguistics:An Ethnographic
Approach. Tavistock Publications Limited.

Ishihara, Masahide dan Eichii Yoshino. (2016). Self-determinable Development of Small Islands. Singapore: Springer Nature.

Mahsun. (2014). Metode Penelitian Bahasa: Tahapan Strategi, Metode dan Tekniknya edisi revisi. Jakarta: PT RajaGrafindo Persada.

Mesthrie, Rajend, Joan Swann, Andrea Deumert \& William L. Leap. (2000). Introducing Sociolinguistics. Edinburgh: Edinburgh Unversity Press.

Mie, Ayako. (2012). Okinawan push to preserve unique language. http://www.japantimes.co.jp/news/ 2012/05/19/national/okinawanspush-to-preserve-uniquelanguage/\#.VOPVbOSYTIV. (accessed on May 20, 2016)

Miller, Robert McColl. (2005). Language and Dialect, in Language, Nation and Power. London: Palgrave Macmillan.

Pateda, Mansoer. (2013). Sosiolinguistik. Bandung: Angkasa.

Sanada, Shinji. (1992). Shakaigengogaku. Tokyo: Oufuu.

Shibatani, Masayoshi. (1990). The language of Japan. Cambridge University Press.

Suryana. (2010). Metodologi Penelitian: Model Praktis Penelitian Kuantitatif dan Kualitatif. Jakarta: Universitas Indonesia.

Uemura, Yukio. (2003). Endangered Languages of the Pacific Rim: The Ryukyuan Language. Translated by 


\section{Kiryoku, Volume 3 No 12019}

e-ISSN: 2581-0960 p-ISSN: 2599-0497

Tersedia online di http://ejournal.undip.ac.id/index.php/kiryoku

Wayne P. Lawrence.Kyoto:

Nakanishi Printing Co.,Ltd.

UNESCO. (2009). Frequent Asked

Questions on Endangered

Languages.

http://www.unesco.org/new/en/cult

ure/themes/endangered-

languages/faq-on-endangered-

languages/. (accessed on January 4 , 2018) 